\title{
El tonograbado: la copiadora de cuadros
}

\author{
El profesor Antonio Navarro crea la primera patente en Bellas Artes de la UMH
}

El profesor de la Universidad Miguel Hernández (UMH) y artista Antonio Navarro ha iniciado los trámites para patentar un sistema de reproducción de grabado. La iniciativa supone la primera patente en el ámbito de Bellas Artes para la UMH. Las pruebas efectuadas con este sistema han dado lugar a una colección de 13 obras relacionadas con el Misteri d'Elx.

La idea surge cuando Antonio Navarro se plantea la posibilidad de pasar sus pinturas a grabado. Para ello, lleva a cabo distintas pruebas bajo la temática del Misteri.

Según el profesor, esta elección responde, por una parte, al deseo de que el espectador reconozca las obras y, en segundo lugar, al afán de estrenar la patente con un homenaje al drama ilicitano. Así, el artista ha empleado materiales como la espátula, el pincel o las aguadas.

La técnica se denomina tonograbado porque permite obtener un amplio espectro de tonalidades.

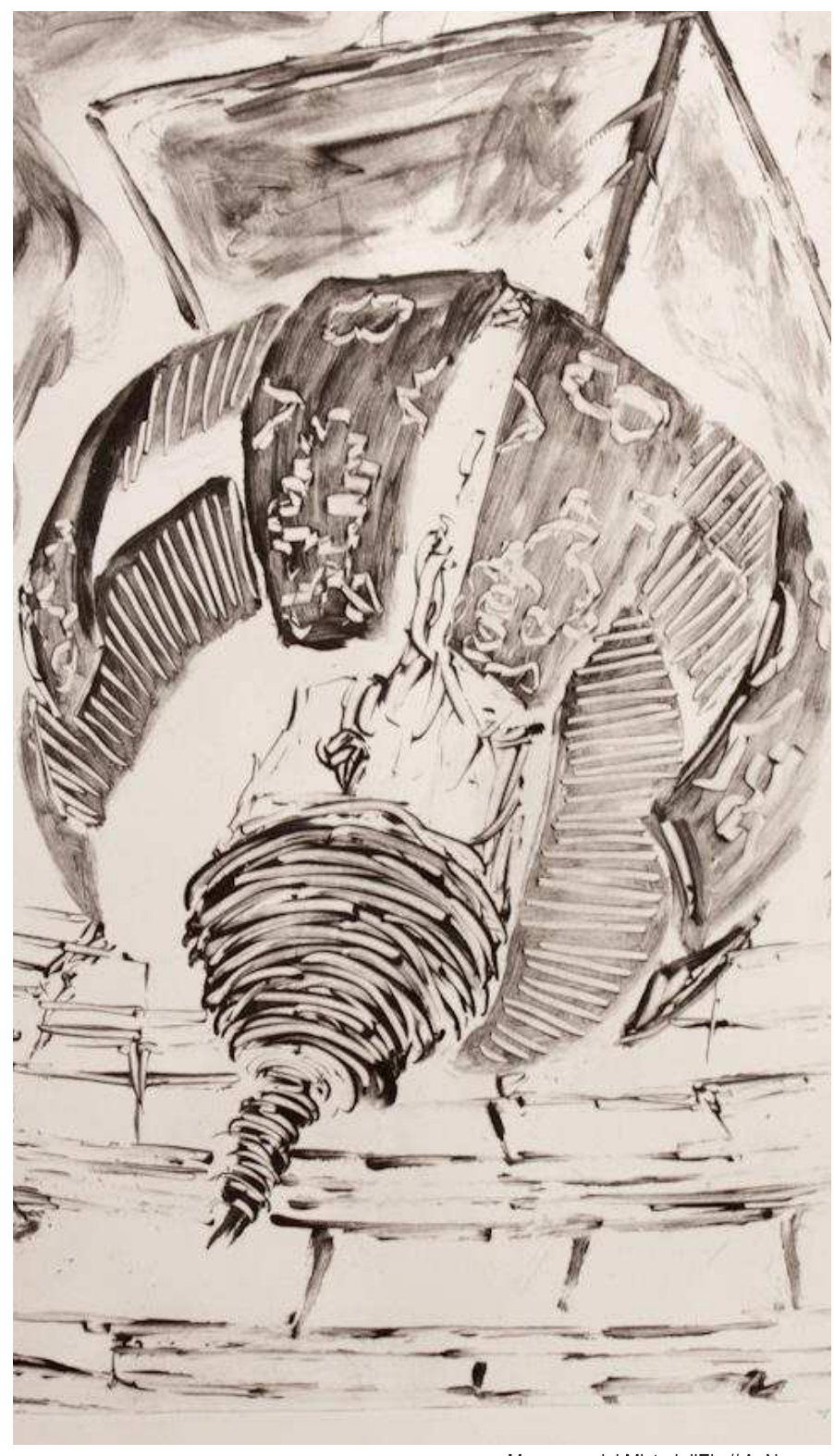

El proceso consiste en trabajar con óleo sobre un soporte flexible de pvc. De esta manera, utilizando una serie de polímeros, se crea una matriz estable con la que reproducir la imagen deseada hasta 120 veces, sin que pierda intensidad. Además, el sistema permite registrar un volumen de cuatro milímetros. A juicio de Navarro: "Se trata de un proceso sencillo pero muy útil, que demuestra que todavía se puede investigar e innovar sobre el grabado".

Mediante el sistema de tonograbado, desarrollado junto a la Universidad de Salamanca, se puede obtener en la reproducción los restos del pincel, así como eliminar o sumar materia. Además de su aplicación para reproducir obras de arte, el procedimiento puede emplearse de forma industrial para estampar papeles decorados. Actualmente, no existe en el mercado otra técnica con la que puedan lograrse estos resultados.

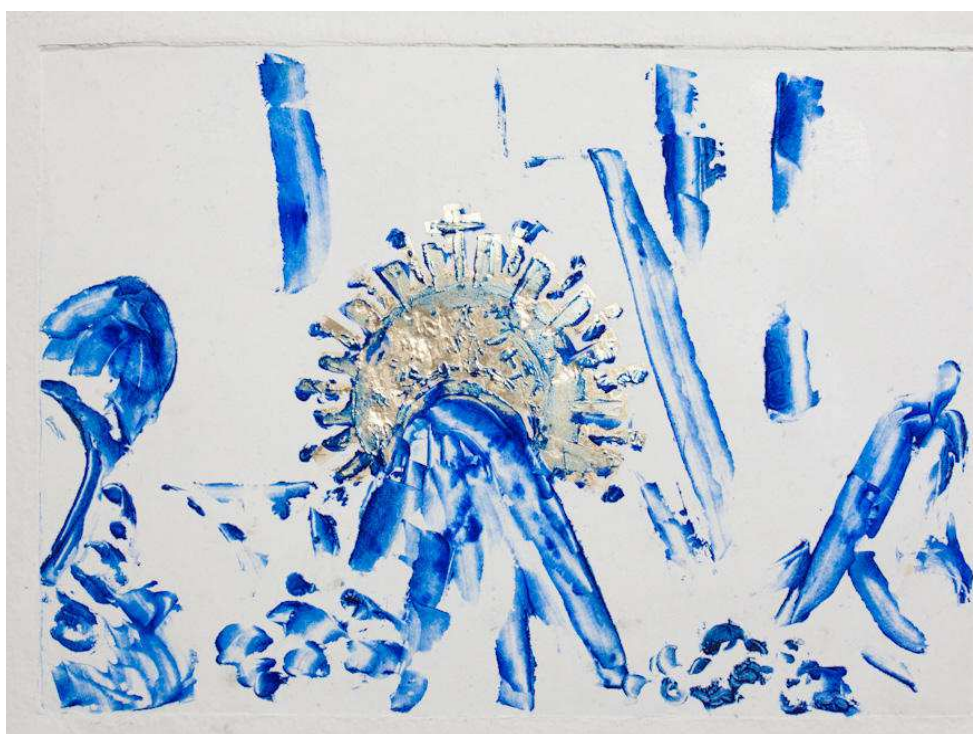

Entrada de las Marías en la Basílical/ A. Navarro

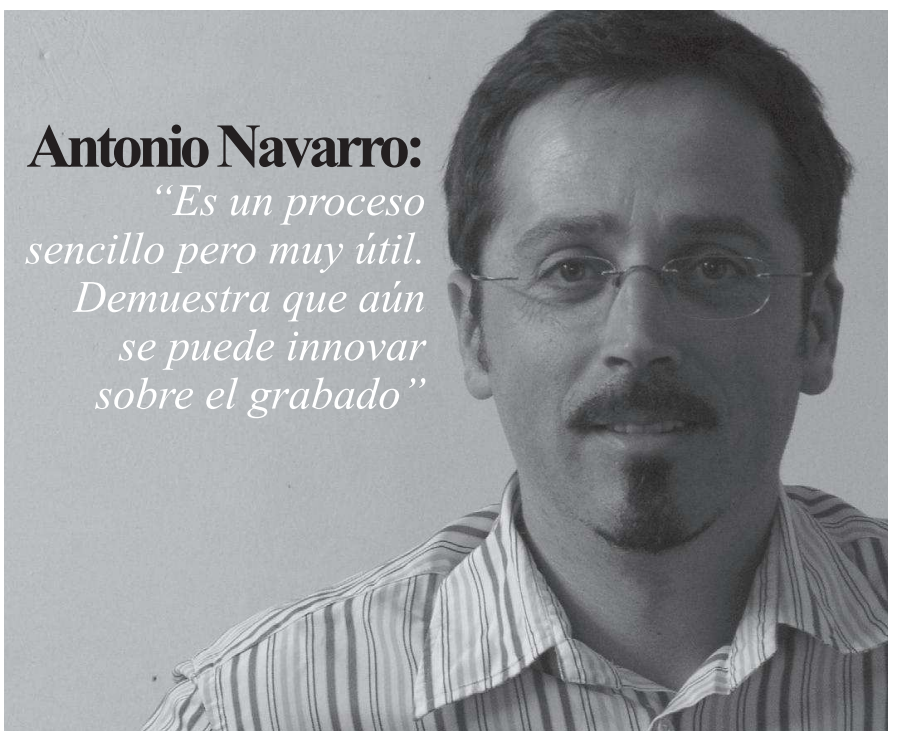

